\title{
UK National Smoking Cessation Conference (UKNSCC) 2007
}

\author{
Andy McEwen \\ Cancer Research UK Health Behaviour Research Centre, University College London
}

Hayden McRobbie

Clinical Trials Research Unit, The University of Auckland and Tobacco Dependence Research \& Treatment Centre, Queen Mary, University of London

It was little more than 3 decades ago that cigarette smoking was still thought of as merely a bad habit that could be 'kicked' if someone put their mind to it. Now tobacco use is recognised as a serious dependence and is considered by many to be a chronic relapsing disease. In response to the significant health gains achieved by stopping smoking a number of countries are integrating smoking cessation treatments into their healthcare systems and an increasing amount of healthcare workers are specialising in this field. The UK National Smoking Cessation Conference (UKNSCC) was created in response to calls from the field for a forum for the exchange of ideas and good practice and to aid professional development. The UKNSCC proved once again in London in 2007 that it is the world's largest gathering of stop smoking practitioners, policy makers and researchers. The UKNSCC is the leading forum for presentations on all types of treatment, service delivery and community-based innovations.

The UKNSCC is delighted to join forces with the Journal of Smoking Cessation to bring you this special conference issue that, in addition to abstracts from all plenary and parallel session, includes invited articles from Alex Bobak on varenicline and the conference keynote oration from John Hughes on redefining the role of cessation specialists. Varenicline is a recent addition to the medicines available to help smokers to stop and, although only able to be prescribed by physicians, smoking cessation specialist play a key role in providing advice and support to both patients and doctors. Dr Bobak highlights the mode of action and efficacy of this medication, and perhaps more importantly, discusses some of the practical issues surrounding the availability and use of varenicline. In his article Professor Hughes redefines the role of the smoking cessation specialists. He makes the case that smoking cessation is a lifesaving treatment for individuals who smoke, as opposed to a population health measure with the goal of reducing smoking prevalence. These points are still widely misunderstood and this article provides support for the continuing professional development of the smoking cessation field.

Plenary presentations were given by international experts such as Eden Evans (US) speaking about smoking and mental health and Renee Bittoun (Australia) on NRT use in the real world. Nancy Rigotti (US) spoke about smoking cessation with hospital in-patients while Kirsten Bell (Canada) presented the NICE review of NHS Smoking Cessation Services. The parallel presentations are a strength of the UKNSCC and included such diverse topics as gradual cigarette reduction using NRT, TEXT2STOP, the geography of demand and supply, shisha pipe smoking, routine $\mathrm{CO}$ monitoring in pregnancy, working with hard-to-reach smokers, and a practical workshop on harm reduction that included snus tasting. All patient groups were covered, including pregnant smokers, young people, those with mental health problems, those in secure environments, and hard-toreach groups. Although smoking cessation is the main focus of the conference, tobacco control measures such as smoke-free public places and harm reduction were also discussed, particularly in relation to how they impact on services helping people to stop smoking.

We anticipate another exciting and informative conference in 2008 at the Birmingham Hilton Metropole on Monday, June 30, and Tuesday, July 1. We look forward to receiving abstract submissions from all those working in smoking cessation via the UKNSCC website (www.uknscc.org) and to seeing you at the 2008 UKNSCC.

Andy McEwen and Hayden McRobbie are Program Directors of the UKNSCC. 